\title{
Identificação e interferência de plantas daninhas em pinhão-manso
}

\author{
Rubens Fey ${ }^{1}$, Deisinara G. Schulz ${ }^{2}$, João A. L. Dranski ${ }^{2}$, \\ José B. Duarte Júnior ${ }^{3}$, Marlene M. Malavasi ${ }^{3}$ \& Ubirajara C. Malavasi ${ }^{3}$
}

\begin{abstract}
RESUMO
Objetivou-se, com este trabalho, avaliar a população de plantas daninhas presentes em pinhão-manso e o período crítico de competição a partir dos 8 meses de transplante no campo. O delineamento utilizado foi em blocos ao acaso em esquema fatorial composto por três procedências e 5 períodos de convivência e de controle das plantas daninhas (0,90, 180, 270 e 360 dias) com 3 repetições. Determinou-se o índice de valor de importância para caracterizar a população de plantas daninhas. O período crítico foi determinado pelo período anterior à convivência (PAI), período total de proteção da interferência (PTPI) e período crítico de proteção à convivência (PCPI) em função das variáveis: diâmetro do caule, diâmetro da copa, ramificações e altura. As perdas máximas admitidas foram de 5 e 10\% de cada variável mensurada. As plantas daninhas encontradas em ordem decrescente de importância foram Sorghum halepense L. Pers, Commelina virginica L., Sida rhombifolia L., Cenchurs echinatus L., Euphorbia heterophylla L., Cenchurs echinatus L. e Boerhavia difusa L. Plantas de pinhão-manso estão sujeitas à redução de suas medidas morfométricas em diâmetro do caule e de copa, número de ramos e de altura, pela interferência de plantas daninhas.
\end{abstract}

Palavras-chave: Jatropha curcas L., crescimento, competição

\section{Identification and interference of weeds in physic nut}

\begin{abstract}
This study aimed to evaluate the weed population and its critical period of competition with physic nut plants eight months after transplanting. The experiment was established in a randomized block design in a factorial scheme composed by three provenances and five periods of coexistence and of weed control $(0,90,180,270$, and 360 days) with three replications. The importance value index was quantified to characterize the weed population. The critical period was determined by PAI (period before interference), PTPI (total period of interference) and CPIC (critical period of weed control) according to the variables: stem diameter, crown diameter, number of branches and plant height. Maximum admitted losses were 5 and $10 \%$ of each measured variable. Weed species in decreasing order of importance were Sorghum halepense L. Pers., Commelina virginica L., Sida rhombifolia L., Brachiaria plantaginea (Link) Hitch, Euphorbia heterophylla L., Cenchrus echinatus L. and Boerhavia diffusa L. Physic nut plants are subject to reduction of their morphometric measures of stem diameter, crown diameter, number of branches and plant height by weed interference.
\end{abstract}

Key words: Jatropha curcas L., growth, competition

' UFFS, BR-158 - km 07, CEP 85.301-970, Laranjeiras do Sul, PR. Fone: (42) 3635-8650, Ramal - 8695. E-mail: rubens.fey@uffs.edu.br 2 PPGA/UNIOESTE, Rua Pernambuco 1777, CEP 85960-000, Marechal Cândido Rondon, PR. Fone: (45) 3284-7911. E-mails: deisi_gs@hotmail.com; joaodranski@yahoo.com.br

${ }_{3}^{3}$ CCA/UNIOESTE. Fone: (45)3284-7878. E-mails: bduarte7@yahoo.com.br; marlenemalavasi@yahoo.com.br; biramalavasi@yahoo.com.br 


\section{INTRODUÇÃO}

O pinhão-manso (Jatropha curcas L.) é uma planta perene com importância econômica pelo potencial de utilização do óleo para a fabricação de biocombustíveis. O principal foco da sua utilização se fixa na produção de biodiesel; no entanto, devido à grande oferta de óleo de soja no mercado o óleo de pinhãomanso é pouco representativo neste setor. Alguns estudos (Eynol, 2009) apontam para a fabricação de bioquerosene para aeronaves a partir do óleo de pinhão-manso, mercado que até o momento não compete com o da soja.

Independentemente da destinação do óleo, a baixa produtividade do pinhão-manso é a maior limitação para a viabilidade dos seus cultivos (Abou-Kheira \& Atta, 2009). Dentre as causas apontadas por pesquisadores estão a variabilidade genética (Rao et al., 2008; Na-Ek et al., 2011), o ataque de pragas e doenças (Franco \& Gabriel, 2008) e a falta de um zoneamento abrangente de plantio (Dallacort et al., 2010).

Os recursos normalmente passíveis de competição entre as plantas daninhas e a cultura, são água, luz e nutrientes. O grau de competição é dependente de fatores ligados à cultura, à comunidade infestante, ao ambiente e ao período de convivência. As fases iniciais de desenvolvimento da cultura após o período anterior à interferência (PAI) são, normalmente, as mais críticas, pois a cultura é rapidamente coberta pelas plantas daninhas e o acesso à radiação fotossinteticamente ativa é restringido.

As espécies de plantas daninhas em determinada área são dependentes do banco de sementes presentes no solo (Vismara et al., 2007) e podem potencializar a competição quando apresentam porte alto e/ou alta densidade e eficiência na captação de nutrientes do solo. O tempo durante o qual plantas daninhas competem com as plantas de interesse foi determinado para uma série de culturas: feijão (Salgado et al., 2007), mandioca (Biffe et al., 2010), quiabo (Santos et al., 2010), cenoura (Soares et al., 2010), sorgo (Rodrigues et al., 2010), eucalipto (Toledo et al., 2000) e milho (Kozlowski et al., 2009).

Os trabalhos através dos quais se avalia o efeito das plantas daninhas no pinhão-manso, são escassos. Pesquisadores observaram que a competição com plantas daninhas na fase inicial de desenvolvimento do pinhão-manso no campo resulta em um diâmetro menor do caule, menor número de ramos (Staut et al., 2011a), menor área de copa e menor altura (Rao et al., 2008). O período crítico de controle da interferência (PCPI) encontrado por Staut et al. (2011b) para evitar perdas da produtividade superior a $10 \%$ em pinhão-manso foi entre $10 \mathrm{e}$ 327 dias após o transplante das mudas ao campo, mas, manter o pinhão-manso livre da competição com plantas daninhas nos primeiros meses de desenvolvimento no campo pode não ser suficiente para evitar perdas de crescimento. Este trabalho objetivou avaliar a população de plantas daninhas presentes na cultura do pinhão-manso e o período crítico de competição a partir de 8 meses do plantio definitivo.

\section{Material e Métodos}

$\mathrm{O}$ experimento foi conduzido em área experimental localizada no município de Pato Bragado, PR, com coordenadas geográficas de $24^{\circ} 39^{\prime \prime} 43^{\prime}$ Sul e $54^{\circ} 13^{\prime} 30^{\prime \prime}$ Oeste e altitude de 563 m. O clima da região, segundo a classificação de Köppen, recebe a denominação de Subtropical Úmido Mesotérmico, com verões quentes (temperatura média superior a $22{ }^{\circ} \mathrm{C}$ ), tendência à concentração de chuvas, invernos com geadas pouco frequentes (temperatura média inferior a $18^{\circ} \mathrm{C}$ ) e precipitação média anual de $1.500 \mathrm{~mm}$.

As plantas foram transplantadas a campo em agosto de 2009 em espaçamento de $3 \times 2 \mathrm{~m}$ sem correção e adubação do solo. A área foi mantida sem interferência com plantas daninhas até dezembro de 2009; entre janeiro e março de 2010 não houve controle de plantas daninhas. O período decorrido desta pesquisa se iniciou em abril de 2010 e terminou em março de 2011. O trabalho constou de dois ensaios: um para testar o efeito da convivência com plantas daninhas e o outro para avaliar o efeito do controle das plantas daninhas em diferentes períodos no desenvolvimento da cultura de pinhão-manso.

$\mathrm{O}$ delineamento utilizado no primeiro ensaio foi em blocos ao acaso com três repetições em esquema fatorial $3 \mathrm{x}$ 5 constituído por materiais de três procedências denominadas Paraguai, Tominaga e Epamig e de cinco épocas de controle das plantas daninhas $(0,90,180,270$, e 360 dias $)$; no segundo ensaio utilizou-se o mesmo delineamento porém com o segundo fator sendo as cinco épocas de convívio do pinhão- manso com as plantas daninhas. A área total da parcela experimental foi de quatro metros quadrados totalizando 90 parcelas (45 para o ensaio de convivência e 45 para o ensaio de controle).

As principais espécies de plantas daninhas presentes na área foram avaliadas em quinze amostras de $0,25 \mathrm{~m}^{2}$ obtidas aleatoriamente. As plantas daninhas foram identificadas quanto à família, gênero e espécie. Adicionalmente, foram determinadas a densidade relativa, a dominância relativa e a frequência relativa e calculado o índice de valor de importância (Ruiz-Valdiviezo et al., 2010) conforme Duarte Júnior et al. (2009). A dominância relativa de cada espécie foi obtida em função da massa seca das plantas daninhas coletadas e secadas em estufa de circulação forçada, na temperatura de $65^{\circ} \mathrm{C}$.

$\mathrm{O}$ controle das plantas daninhas foi realizado manualmente com auxílio de enxada, de acordo com os tratamentos. No início e ao final dos ensaios as avaliações constaram da altura e diâmetro do caule do pinhão-manso mensurados com auxílio de paquímetro e trena. O número total de ramos e o diâmetro da copa do pinhão-manso foram quantificados somente ao final do período dos ensaios com o auxílio de trena.

Os dados foram submetidos à análise de variância aplicandose o teste $\mathrm{F}$ em nível de 0,05 de probabilidade e, quando da existência de diferenças significativas para a variável independente (procedências) foi aplicado o teste de Tukey em nível de $5 \%$ de probabilidade. Para as variáveis épocas de convivência e controle de plantas daninhas foi realizada análise de regressão sigmoidal. As equações ajustadas obedeceram aos pressupostos de significância e normalidade. Os limites para os períodos de interferência (período anterior à interferência - PAI, período crítico de prevenção à interferência - PCPI e período total de prevenção à interferência - PTPI) foram determinados admitindo-se perda máxima de 5 e $10 \%$ para cada variável estudada, em comparação às parcelas mantidas 
sem interferência com as plantas daninhas, por todo o período experimental.

\section{Resultados E Discussão}

A família de plantas infestante mais observada entre o pinhão-manso neste trabalho, foi a Poaceae (Tabela 1). Esta família, representada por Cenchurs echinatus L., Brachiaria plantaginea (Link) Hitchc. e Sorghum halepense (L.) Pers. também esteve presente nas áreas circunvizinhas à experimental de onde possivelmente se originaram as sementes.

Tabela 1. Relação de plantas daninhas distribuídas por família e espécie presentes no experimento com pinhão-manso

\begin{tabular}{lll}
\hline \multicolumn{1}{c}{ Família } & \multicolumn{1}{c}{ Nome científico } & \multicolumn{1}{c}{ Nome comum } \\
Commelinaceae & Commelina virginica L. & Trapoeraba \\
Euphorbiaceae & Euphorbia heterophylla L. & Amendoim bravo \\
Malvaceae & Sida rhombifolia L. & Guanxuma \\
Nyctaginaceae & Boerhavia difusa L. & Erva-tostão \\
Poaceae & Cenchurs echinatus L. & Capim-carrapicho \\
Poaceae & Brachiaria plantaginea (link) Hitchc. Capim-marmelada \\
Poaceae & Sorghum halepense (L.) Pers. & Capim massarambá \\
\hline
\end{tabular}

Dentre as plantas daninhas presentes na área, Sorghum halepense (L.) Pers. foi a mais representativa (Figura 1). Esta planta daninha foi observada com maior frequência e em maior massa nas parcelas experimentais. A espécie S.halepense apresenta crescimento rápido e na fase adulta ultrapassa os $2 \mathrm{~m}$ de altura (Lorenzi, 2006) altura suficiente para sombrear parte das folhas do pinhão-manso resultando, possivelmente, em menor disponibilidade de radiação fotossinteticamente ativa à disposição da cultura principal.

A Commelina virginica $\mathrm{L}$. foi a segunda espécie mais presente entre o pinhão-manso (Figura 1). A densidade e a frequência relativa foram semelhantes às do Sorghum halepense (L.) Pers., porém, pelo baixo porte e folhas tenras, obteve menos da metade da dominância (matéria seca) do capim. Não há descrição, na literatura, de que esta invasora poderia prejudicar o desenvolvimento do pinhão-manso. A espécie C.virginica é descrita como planta daninha para culturas anuais e perenes (Dias et al., 2005) por dificultar a colheita e conferir excesso de umidade aos grãos.

A Sida rhombifolia L. apresentou importância intermediária na classificação do IVI entre todas as espécies podendo indicar

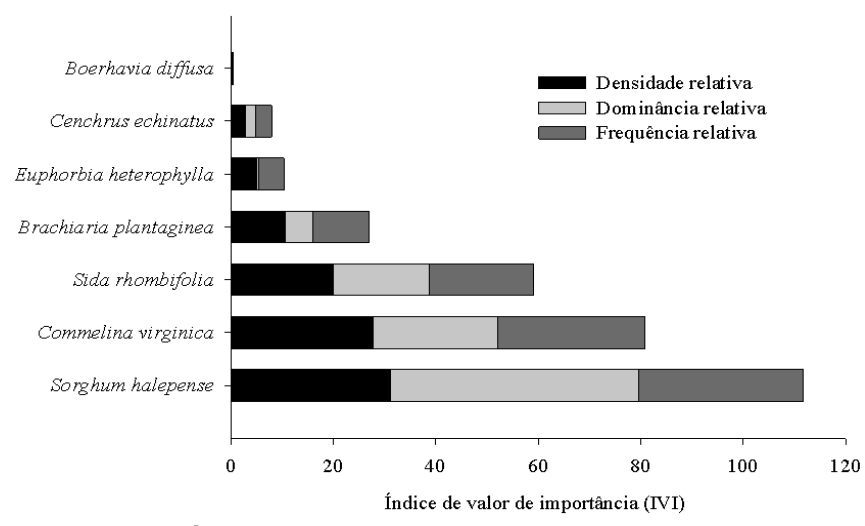

Figura 1. Índice de valor de importância das espécies de plantas daninhas encontradas na área experimental

presença de camada compactada no solo (Casalinho et al., 2007). As espécies Euphorbia heterophylla L., Boerhavia diffusa L. e Cenchurs echinatus L. apesar de presentes, possivelmente não causaram interferência na cultura do pinhão-manso pelo seu baixo IVI.

A presença de plantas infestantes entre as plantas de pinhão-manso causou diferença nas variáveis morfométricas analisadas (Tabela 2). Este resultado foi semelhante para todas as procedências (Epamig, Paraguai e Tominaga) testadas, com exceção do incremento em altura no período de convivência com as infestantes.

As sementes da procedência Paraguai originaram plantas que se desenvolveram mais quando cresceram em convivência com plantas infestantes (Tabela 3). Este resultado pode representar uma seleção genética conferida pela adaptação ao local do ensaio que faz divisa com o Paraguai. As condições climáticas em que foram produzidas as sementes do pinhãomanso procedência Tominaga, são classificadas como tropical enquanto a região deste ensaio é subtropical. O maior

Tabela 3. Incremento em altura e média de cinco períodos de convivências com plantas daninhas, de procedências de pinhão-manso

\begin{tabular}{cc}
\hline Procedência & Incremento em altura (m) \\
Paraguai & $1,580 \mathrm{a}$ \\
Epamig & $1,426 \mathrm{ab}$ \\
Tominaga & $1,295 \mathrm{~b}$ \\
\hline DMS & 0,175 \\
\hline
\end{tabular}

DMS: Diferença mínima significativa; médias seguidas de mesma letra na coluna não diferem pelo teste de Tukey a 0,05 de probabilidade

Tabela 2. Resumo da análise de variância dos incrementos em altura e coleto, número de ramos e diâmetro de copa dos experimentos com diferentes períodos de convivência (conviv.) e controle (contr.) de plantas daninhas em área com três procedências de pinhão-manso

\begin{tabular}{|c|c|c|c|c|c|c|c|c|c|}
\hline \multirow{3}{*}{$\begin{array}{l}\text { Fonte de } \\
\text { variação }\end{array}$} & \multirow{3}{*}{ GL } & \multicolumn{4}{|c|}{ Incremento } & \multirow{2}{*}{\multicolumn{2}{|c|}{ Número de ramos }} & \multirow{2}{*}{\multicolumn{2}{|c|}{ Diâmetro da copa }} \\
\hline & & \multicolumn{2}{|c|}{ Altura } & \multicolumn{2}{|c|}{ Caule } & & & & \\
\hline & & Conviv. & Contr. & Conviv. & Contr. & Conviv. & Contr. & Conviv. & Contr. \\
\hline & & \multicolumn{8}{|c|}{ Quadrado médio } \\
\hline Blocos & 2 & $0,124^{\text {ns }}$ & $0,174^{\text {ns }}$ & $0,326^{\text {ns }}$ & $0,565^{\text {ns }}$ & $46,822^{\text {ns }}$ & $3,467^{\mathrm{ns}}$ & $0,088^{\text {ns }}$ & $0,307^{\text {ns }}$ \\
\hline Período & 4 & $0,057^{\mathrm{ns}}$ & $0,174^{*}$ & $2,486^{\star}$ & 4,500 * & $102,133^{* *}$ & $56,856^{\star}$ & 1,424 ** & $0,705^{*}$ \\
\hline Procedência & 2 & $0,306^{* *}$ & $0,108^{\text {ns }}$ & $1,776^{\text {ns }}$ & $0,287^{\text {ns }}$ & $23,022^{\text {ns }}$ & $34,867^{\text {ns }}$ & $0,285^{\text {ns }}$ & $0,588^{\text {ns }}$ \\
\hline Interação & 8 & $0,061^{\mathrm{ns}}$ & $0,073^{\text {ns }}$ & $1,079^{\text {ns }}$ & $0,574^{\text {ns }}$ & $6,217^{\text {ns }}$ & $21,339^{\text {ns }}$ & $0,130^{\text {ns }}$ & $0,261^{\text {ns }}$ \\
\hline CV\% & & 13,55 & 18,49 & 19,43 & 27,02 & 62,42 & 41,47 & 60,42 & 41,04 \\
\hline Média geral & & 1,43 & 1,35 & 4,48 & 4,23 & 7,42 & 9,80 & 0,89 & 1,13 \\
\hline
\end{tabular}

ns: não significativo; ${ }^{* \star} \mathrm{e}^{*}$ : significativo a $0,01 \mathrm{e} 0,05$ respectivamente; CV: coeficiente de variação 
crescimento em altura pode conferir, à procedência Paraguai, maior tolerância na convivência com outras plantas comparada às procedências do estado de Minas Gerais (Tominaga e Epamig) quando plantadas em regiões com clima subtropical.

A interferência das plantas daninhas no desenvolvimento das plantas de pinhão- manso pode comprometer o crescimento e o desenvolvimento vegetativo assim como a quantidade e a qualidade do óleo das sementes. Arruda et al. (2004) indicaram que o pinhão-manso exige tratos culturais intensos principalmente no período crítico de competição com as plantas daninhas.

Os efeitos danosos das plantas daninhas à cultura do pinhão-manso são vários, desde os diretos aos indiretos. Como efeitos diretos se destacam a competição por água e nutrientes que prejudicam significativamente a atividade fotossintética e a nutrição mineral das plantas de pinhão-manso, haja vista que reduzem mais rapidamente a disponibilidade de água e nutrientes no sistema solo. Adicionalmente, a competição por luz exerce influência, sobretudo se houver ocorrência de plantas com características de trepadoras, a exemplo do gênero Ipomoea spp. Neste contexto existe o possível efeito alelopático conferido pelas plantas daninhas às culturas de interesse comercial (Souza et al., 2003).

Vale ressaltar ainda que, em função da ampla base genética, as plantas daninhas são mais rústicas e apresentam estruturas reprodutivas altamente prolíferas e de fácil disseminação. Como danos indiretos verificam-se, por espécies ocorrentes como a Commelina virginica, comumente denominada trapoeraba, a qual é hospedeira de nematóides Meloydogyne incognita, Pratylenchus pratensis, fungos como Piricularia grisea e vírus, além de apresentar alto grau de resistência ao herbicida glyphosate. As espécies como Ipomoea grandifoli, Cyperus rotundus, Solum americanum, Echinochloa colonum, Raphanus raphanistrum, Sorghum halepense, Galinsoga ciliata e Eleusine indica são excelentes para a reprodução e multiplicação de Meloidogyne paranaensis (Roese \& Oliveira, 2004). A espécie Sida rhombifolia, além de rebrotar com facilidade hospeda o vírus do mosaico-dourado que afeta culturas como o feijão, a soja e o algodão.

$\mathrm{O}$ incremento do caule foi maior nas parcelas com menos interferência de plantas infestantes (Figura 2). A determinação das datas limite para o PAI (período anterior à convivência), do PTPI (período total de prevenção a interferência) e do PCPI (período crítico de prevenção a interferência) baseou-se na perda de 5 e $10 \%$ do incremento nas parcelas sem a competição com plantas daninhas. O diâmetro do caule possui correlação direta com a produtividade em pinhão-manso (Fey et al., 2012) mas para o pinhão-manso o limite (5 e 10\%) é teórico pois não existe definição da porcentagem de perda que justifique, economicamente, o controle da matocompetição.

Ao se considerar uma perda aceitável de $5 \%$, o PAI para incremento do caule é de 78 dias e para 10\% de 107 dias (Figura $2 \mathrm{~A}, \mathrm{~B})$. Até este período as perdas causadas pela interferência de plantas infestantes podem não justificar gastos com seu controle. Em eucalipto Victória Filho (1987) observou que a competição com a planta daninha também reduziu o diâmetro do caule e, consequentemente, o volume colhido aos 38 meses.

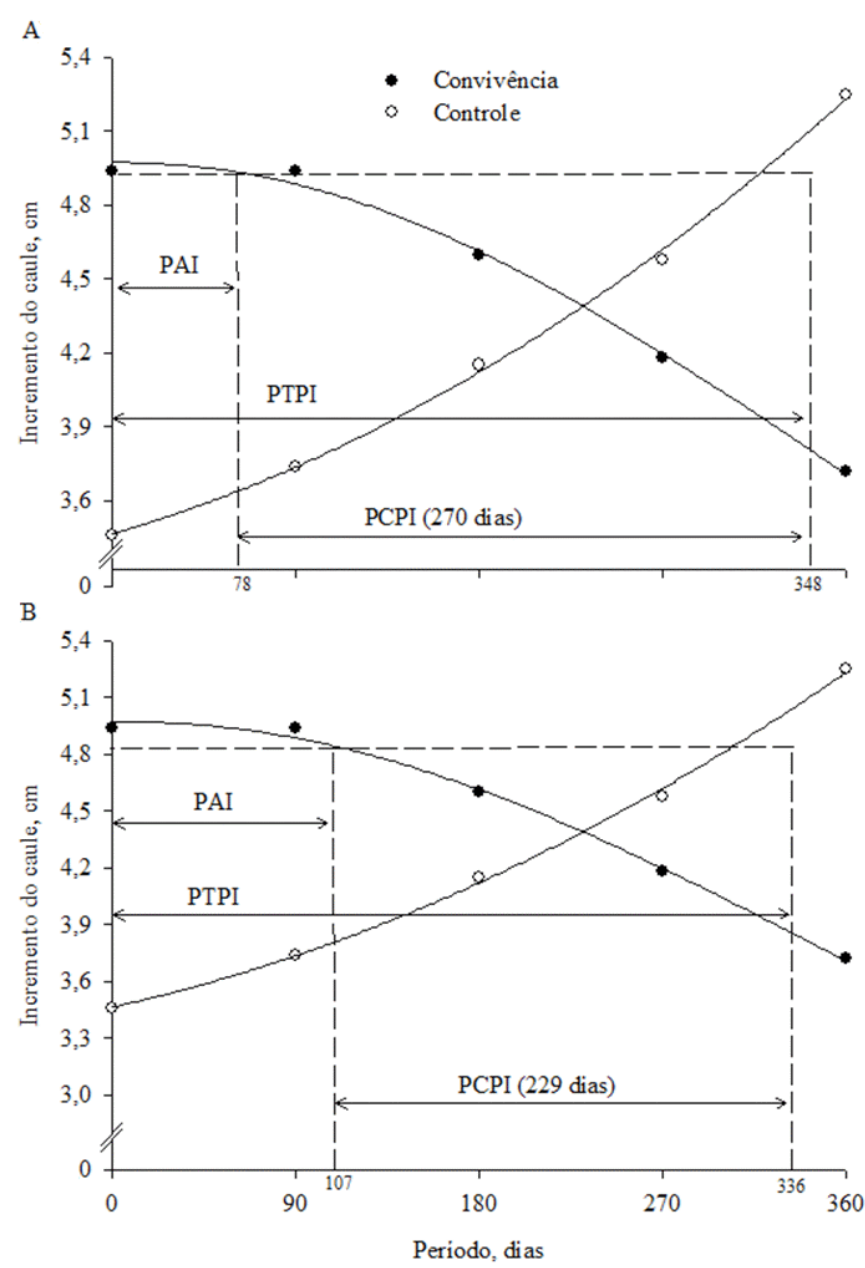

Figura 2. Incremento em diâmetro de caule, média de três procedências de pinhão- manso para diferentes períodos de controle e convivência com plantas daninhas considerando-se as perdas em incremento do caule, de $5 \%$ (A) e $10 \%$ (B)

O PAI encontrado para o eucalipto por Toledo et al. (2000) foi de 14 dias após o plantio para o diâmetro do caule. Staut et al. (2011a) também observaram redução no diâmetro do caule em pinhão-manso em função da competição com plantas daninhas logo após o transplante a campo. O diferencial deste ensaio é o período de avaliação que se iniciou com plantas com 8 meses de implantação a campo e com o diâmetro inicial de $2 \mathrm{~cm}$ em média (Dranski, 2010).

O PCPI calculado pelas equações de incremento do caule (Tabela 4) foi de 270 e 229 dias, menor e maior porcentagem de perda, respectivamente. Neste período deveria ter ocorrido o controle das plantas infestantes no pinhão-manso. Na mamona da mesma família botânica do pinhão-manso Milani et al. (2010) encontraram uma correlação de $0,88(p<0,01)$ entre o diâmetro do caule e a produtividade. Tonini et al. (2008) observaram que a produção de sementes de castanha do Brasil foi crescente e se correlacionou com o diâmetro do caule; portanto, perdas futuras de produtividade podem ocorrem no pinhão-manso, por interferência de plantas daninhas.

A redução no diâmetro da copa foi acentuada pela convivência com plantas invasoras (Figura 3). Dois e quatro dias foram os limites para realizar o controle do mato a fim de 
Tabela 4. Modelos, coeficientes, ajustes e teste F utilizados na determinação do PAI, PTPI e PCPC do Incremento do caule e altura, diâmetro da copa e número de ramos de pinhão-manso, média de três procedências em diferentes períodos de controle e convivência com plantas daninhas

\begin{tabular}{|c|c|c|c|c|}
\hline Variável & Período ${ }^{1}$ & Modelo & $\mathbf{R}^{2}$ & Probabilidade \\
\hline \multirow{3}{*}{ Incremento do caule $(\mathrm{IC})$} & & IC $-\quad 4.973$ & & \\
\hline & Convivência & $\mathrm{IC}=\overline{1+\left(\frac{\mathrm{x}}{597049}\right)^{2.12}}$ & 0,995 & 0,0015 \\
\hline & Controle & $\begin{array}{c}\mathrm{IC}=3.4645+0.0024 \mathrm{x}+0.0000070 \mathrm{x}^{2} \\
1.567\end{array}$ & 0,999 & 0,0120 \\
\hline \multirow{3}{*}{ Diâmetro da copa (DC) } & Convivência & $\mathrm{DC}=\overline{1+\left(\frac{\mathrm{x}}{156.346}\right)^{0.615}}$ & 0,994 & 0,0079 \\
\hline & & 1.3993 & & \\
\hline & Controle & $\mathrm{DC}=\frac{}{1+\mathrm{e}^{-\left(\frac{\mathrm{x}-1.9223)}{90.7087}\right)}}$ & 0,955 & 0,0400 \\
\hline Número de ramos & Convivência & $\mathrm{NR}=\frac{1+\left(\frac{\mathrm{x}}{136.641}\right)^{0.516}}{1+10 ?}$ & 0,994 & 0,0058 \\
\hline Incremento em altura $(\mid A)$ & Controle & $\mathrm{IA}=1.0979+\frac{1.4423}{1+\mathrm{e}^{-\left(\frac{\mathrm{x}-518.9190}{205.6516}\right)}}$ & 0,999 & 0,0120 \\
\hline
\end{tabular}

${ }^{1}$ Expresso em dias $(\mathrm{x})$

que as perdas não fossem superiores a 5 e $10 \%$, respectivamente (Figura 2 A,B). O diâmetro da copa é proporcionado pelo número e arqueamento dos ramos do pinhão-manso. Aos 80 dias, o diâmetro de copa reduziu $50 \%$ em comparação às plantas com zero dia de convivência (Figura 3).
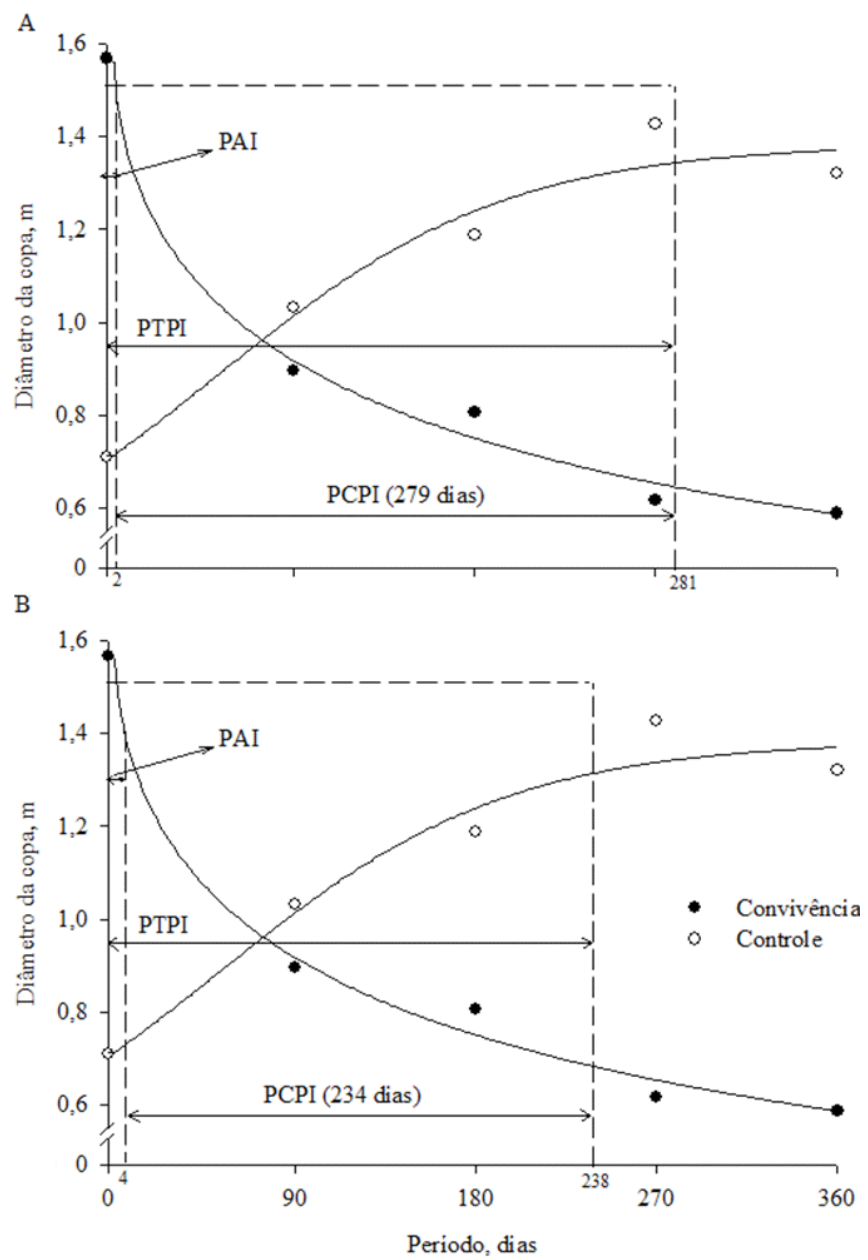

Figura 3. Diâmetro da copa e média de três procedências de pinhão-manso para diferentes períodos de controle e convivência com plantas daninhas considerando-se as perdas em diâmetro da copa de 5\% (A) e 10\% (B)

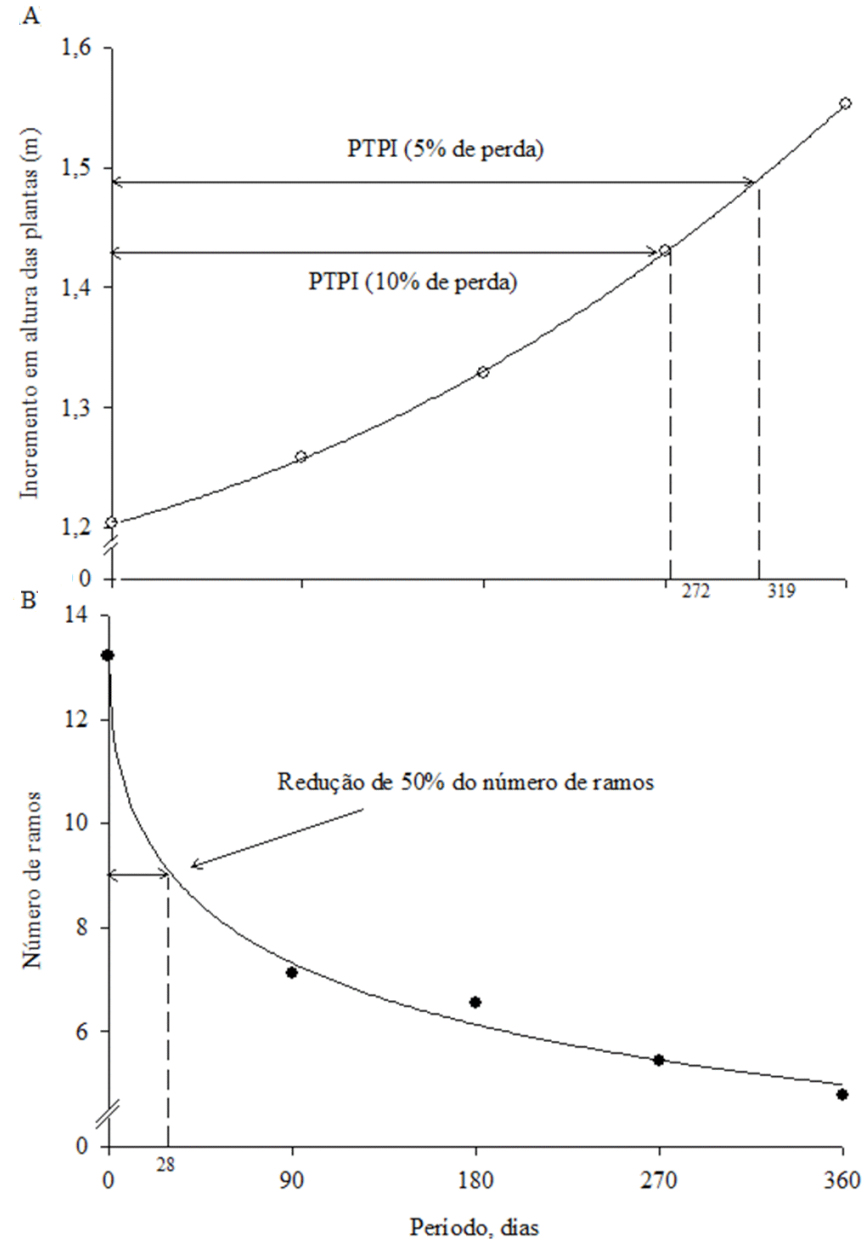

Figura 4. Incremento em altura (A) e número de ramos (B), média de três procedências de pinhão-manso, para diferentes períodos de interferência de plantas daninhas

Um efeito da redução de copa foi a redução na formação de ramos (Figura 3B). Ocorreu uma perda significativa na emissão de novos ramos chegando a $50 \%$ aos 28 dias em relação ao tratamento com 360 dias de convivência com plantas invasoras; esta perda reforça a explanação anterior de que o diâmetro da 
copa tem relação direta com a emissão de ramos laterais. As inflorescências do pinhão-manso ocorrem nas extremidades dos ramos e quanto maior o número de ramos maior também o número de inflorescências as quais, se mantidas e fecundadas, resultarão em maior produção por planta (Rao et al., 2008). Staut et al. (2011b) também observaram que existe uma redução drástica do número de ramos em plantas de pinhão-manso em competição com plantas daninhas.

O crescimento em altura do pinhão-manso foi mais intenso na ausência de plantas daninhas (Figura 4A). Este resultado corrobora com os obtidos por Staut et al. (2011a) que também obtiveram redução em altura do pinhão-manso pelo efeito da competição com plantas daninhas, porém a procedência Paraguai foi a menos desfavorecida e externou maior crescimento em altura comparado com as demais procedências (Tabela 3). Este resultado pode não representar um ganho em produtividade. Estudos com poda estão sendo são realizados para controlar o tamanho e estimular a ramificação das plantas de pinhão-manso (Oliveira \& Beltrão, 2010).

\section{Conclusões}

1. As plantas daninhas reduziram significativamente o crescimento de pinhão- manso em áreas com cultivo já estabelecido.

2. O controle da interferência de plantas daninhas em pinhão-manso deve prolongar-se até pelo menos 20 meses após o plantio das mudas a campo para evitar perdas no crescimento do diâmetro da copa, diâmetro do caule, altura e número de ramificações.

\section{Literatura Citada}

Abou-Kheira, A. A.; Atta, N. M. M. Response of Jatropha curcas L. to water deficits: Yield, water use efficiency and oilseed characteristics. Biomass and Bioenergy, v.33, p.1343-1350, 2009.

Arruda, F. P.; Beltrão, N. E. de M.; Andrade, A. P.; Pereira, W. E.; Severino, L. S. Cultivo de pinhão manso (Jatropha curcas) como alternativa para o semiárido nordestino. Revista Brasileira de Oleaginosas e Fibrosas, v.8, p.789799, 2004.

Biffe, D. F.; Constantin, J.; Oliveira Júnior, R. S.; Franchini, L. H. M.; Rios, F. A.; Blainski, E.; Arantes, J. G. Z.; Alonso, D. G.; Cavalieri, S. D. Período de interferência de plantas daninhas em mandioca (Manihot esculenta) no noroeste do Paraná. Planta Daninha, v.28, p.471-478, 2010.

Casalinho, H. D.; Martins, S. R.; Lopes, Â. D. S. Qualidade do solo em sistemas de produção de base Ecológica: A percepção do agricultor. Revista Brasileira de Agroecologia, v.2, p.59-62, 2007.

Dallacort, R.; Martins, J. A.; Inoue, M. H.; Freitas, P. S. L.; Krause, W. Aptidão agroclimática do pinhão manso na região de Tangará da Serra, MT. Revista Ciência Agronômica, v.41, p.373-379, 2010.

Dias, T. C. S.; Alves, P. L. C. A.; Lemes, L. N. Períodos de interferência de Commelina benghalensis na cultura do café recém-plantada. Planta Daninha, v.23, p.397-404, 2005.
Dranski, J. A. L. Sobrevivência e crescimento inicial de pinhão-manso em função da época de plantio e do uso de hidrogel. Marechal Cândido Rondon: UNIOESTE, 2010. 57p. Dissertação Mestrado

Duarte Júnior, J. B.; Coelho, F. C.; Freitas, S. D. P. Dinâmica de populações de plantas daninhas na cana-de-açúcar em sistema de plantio direto e convencional. Semina: Ciências Agrárias, v.30, p.595-612, 2009.

Eynol, F. Modelo do biodiesel poderia ser aplicado ao querosene vegetal. Inovação Uniemp, v.3, p.21-23, 2009.

Fey, R.; Schultz, D. G.; Dranski, J. A. L.; Istchuk, A. N.; Malavasi, M. M.; Malavasi, U. C. Produtividade de pinhão manso e sua relação com o diametro do caule. In: Congresso da Rede Brasileira de Tecnologia de Biodiesel, 5, 2012, Salvador. Anais...CRBTB, 2012. p.97-98.

Franco, D. A. S.; Gabriel, D. Aspectos fitossanitários na cultura do pinhão manso (Jatropha curcas L.) para produção de biodiesel. Biológico, v.70, p.63-64, 2008.

Kozlowski, L. A.; Koehler, H. S.; Pitelli, R. A. Épocas e extensões do período de convivência das plantas daninhas interferindo na produtividade da cultura do milho (Zea mays). Planta Daninha, v.27, p.481-490, 2009.

Lorenzi, H. Manual de identificação e controle de plantas daninhas. 6.ed. Nova Odessa: Instituto Plantarum de Estudos da Flora Ltda., 2006. 339p.

Milani, M.; Nóbrega, M. B. D. M.; Andrade, F. P. D. Correlação entre características de interesse econômico em mamoneira. In: Congresso Brasileiro de Mamona, 4 Simpósio Internacional de Oleaginosas Energéticas, 1, 2010, João Pessoa. Anais...João Pessoa: Embrapa Algodão, 2010. p.1670-1674.

Na-Ek, Y; Wongkaew, A.; Phumichai, T.; Kongsiri, N.; Kaveeta, R.; Sreewongchai T.; Phumichai, C. Genetic diversity of physic nut (Jatropha curcas L.) revealed by SSR markers. Journal of Crop Science and Biotechnology, v.14, p.105$110,2011$.

Oliveira, S. J. C.; Beltrão, N. E. de M. Crescimento do pinhão manso (Jatropha curcas) em função da poda e da adubação química. Revista Brasileira de Oleaginosas e Fibrosas, v.14, p.9-17, 2010.

Rao, G. R; Korwar, G. R.; Shanker, A. K.; Ramakrishna, Y. S. Genetic associations, variability and diversity in seed characters, growth, reproductive phenology and yield in Jatropha curcas (L.) accessions. Trees, v.22, p.697-709, 2008.

Rodrigues, A. C. P.; Costa, N. V.; Cardoso, L. A.; Campos, C. F.; Martins, D. Períodos de interferência de plantas daninhas na cultura do sorgo. Planta Daninha, v.28, p.23-31, 2010.

Roese, A. D.; Oliveira, R. D. de L. Capacidade reprodutiva de Meloidogyne paranaensis em espécies de plantas daninhas. Nematologia Brasileira, v.28, p.137-141, 2004.

Ruíz-Valdiviezo, V. M.; Luna-Guido, M.; Galzy, A.; GutiérrezMiceli, F. A.; Dendooven, L. Greenhouse gas emissions and $\mathrm{C}$ and $\mathrm{N}$ mineralization in soils of Chiapas (Mexico) amended with leaves of Jatropha curcas L. Applied Soil Ecology, v.46, p.17-25, 2010.

Salgado, T. P.; Salles, M. S.; Martins, J. V. F.; Alves, P. L. C. A. Interferência das plantas daninhas no feijoeiro carioca. Planta Daninha, v.25, p.443-448, 2007. 
Santos, J. B.; Silveira, T. P.; Coelho, P. S.; Costa, O. G.; Matta, P. M.; Silva, M. B.; Drumond Neto, A. P. Interferência de plantas daninhas na cultura do quiabo. Planta Daninha, v.28, p.255-262, 2010.

Soares, I. A. A.; Freitas, F. C. L.; Negreiros, M. Z.; Freire, G. M.; Aroucha, E. M. M.; Grangeiro, L. C.; Lopes, W. A. R.; Dombroski, J. L. D. Interferência das plantas daninhas sobre a produtividade e qualidade de cenoura. Planta Daninha, v.28, p.247-254, 2010.

Souza, L. S.; Velini, E. D.; Maiomoni-Rodella, R. C. S. Efeito alelopático de plantas daninhas e concentração de capim braquiária (Brachiaria decumbens) no desenvolvimento inicial de eucalipto (Eucalyptus grandis). Planta Daninha, v.21, p.343-354, 2003.

Staut, L. A.; Silva, C. J.; Concenço, G. Crescimento de plantas de pinhão-manso sob competição com plantas daninhas: 2 Caule e ramificações. In: Congresso Brasileiro de Pesquisas de Pinhao Manso, 2., 2011, Brasília. Anais...Brasília: Embrapa Agroenergia, 2011a.
Staut, L. A.; Silva, C. J.; Concenço, G. Influência da competição interespecífica no crescimento de pinhão-manso. In: Congresso Brasileiro de Pesquisas de Pinhão Manso, 2, 2011, Brasília. Anais. Brasília: Embrapa Agroenergia, 2011b.

Toledo, R. E. B.; Victória Filho, R.; Pitelli, R. A.; Alves, P. L. C. A.; Lopes, M. A. F. Efeito de períodos de controle de plantas daninhas sobre o desenvolvimento inicial de plantas de eucalipto. Planta Daninha, v.18, p.395-404, 2000.

Tonini, H.; Kaminski, P. E.; Costa, P. D. Relação da produção de sementes de castanha-do-brasil com características morfométricas da copa e índices de competição. Pesquisa Agropecuária Brasileira, v.43, p.1509-1516, 2008.

Victória Filho, R. Influência da matocompetição em plantios de Eucalyptus grandis. Série Técnica IPEF, v.4, p.25-35, 1987.

Vismara, L.; Oliveira, V.; Karam, D. Revisão de modelos matemáticos da dinâmica do banco de sementes de plantas daninhas em agrossistemas. Planta Daninha, v.25, p.1-11, 2007. 